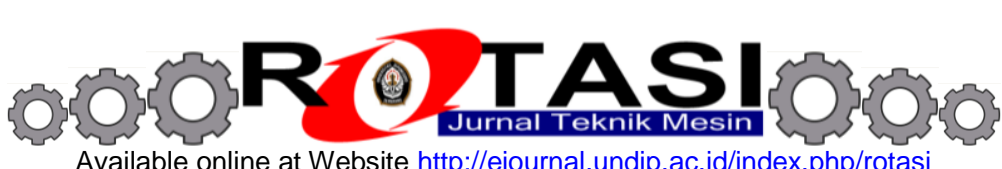

Available online at Website http://ejournal.undip.ac.id/index.php/rotasi

\title{
RANCANG ULANG HEAT EXCHANGER SHELL AND TUBE PADA PRESSURE REDUCING SYSTEM UNTUK COMPRESSED NATURAL GAS KAPASITAS $150 \mathrm{~m}^{3} / \mathrm{Jam}$
}

\author{
*Anwar Ilmar Ramadhana, Syawaluddina, Ery Diniardia, Dalil Sumiyarsonob \\ aJurusan Teknik Mesin, Fakultas Teknik, Universitas Muhammadiyah Jakarta \\ ${ }^{\mathrm{b}}$ Mahasiswa Jurusan Teknik Mesin, Fakultas Teknik, Universitas Muhammadiyah Jakarta \\ Jl. Cempaka Putih Tengah No 27 Jakarta 10510 \\ *E-mail: anwar.ilmar@ftumj.ac.id
}

\begin{abstract}
Reduce the pressure and reheating CNG, created a tool called a pressure reducing system (PRS) which consists of a pressure reducing regulator, heating CNG or we call this section with heat exchanger and measuring tools or gas meter. In connection with this task, will be discussed on the heat exchanger in the heat of this CNG. In this study, a survey was conducted on the heat exchanger Pressure Reducing System (PRS) is installed with a capacity of $200 \mathrm{~m}^{3} / \mathrm{h}$, while the use of CNG for the production process is $150 \mathrm{~m}^{3} / \mathrm{h}$. CNG temperature after coming out of the PRS read on the thermometer is at $50^{\circ} \mathrm{C}$. From these data it can be concluded that the heat exchanger is greater than the required capacity. In order to get heat exchanger in accordance with the capacity of $150 \mathrm{~m}^{3} / \mathrm{h}$ will be redesigned according to the capacity. From the data obtained it can be concluded that the pressure reducing system capacity greater use of capacity will value of higher effectiveness at about 90\%. As for usage as needed obtained effectiveness of $70 \%$. The advantages that can be drawn is that the efficiency in terms of construction materials and a smaller space than the existing PRS.
\end{abstract}

Keywords: Heat exchanger, PRS, CNG, Effectiveness, Pressure

\section{PENDAHULUAN}

Dalam dunia industri diperlukan bahan bakar faktor utama sebagai penggeraknya. Compressed Natural Gas (CNG) adalah salah satu bahan bakar yang digunakan oleh industri. CNG ini berasal dari natural gas yang dimampatkan didalam tabung-tabung sampai dengan tekanan 200 bar, sehingga temperatur mencapai $-40^{\circ} \mathrm{C}$ [1].

Untuk menurunkan tekanan dan memanaskan kembali $\mathrm{CNG}$, dibuatkan alat yang disebut pressure reducing system (PRS) dimana terdiri dari regulator sebagai penurun tekanan, pemanas CNG atau biasa kita sebut bagian ini dengan heat exchanger dan alat ukur atau meter gas. Dalam kaitannya dengan tugas ini, akan dibahas mengenai heat exchanger dalam proses memanaskan CNG ini [2].

Pada proses ini sebagai fluida yang dipanaskan adalah CNG yang mengalir melalui tube dan sebagai pemanas adalah air yang berada di dalam kotak tanpa tekanan. Heat exchanger yang dipakai dalam proses ini adalah tipe shell \& tube. Heat exchanger yang terpasang pada pressure reducing system (PRS) ini dibuat dalam berbagai ukuran, tergantung kapasitas gasnya. Karena harga PRS cukup tinggi, maka sering kali di lapangan oleh CNG Provider dipasang PRS yang tidak sesuai dengan kapasitasnya. Kebanyakan dipasang lebih besar dari kapasitas pemakaian sebenarnya atau bisa dikatakan tergantung dari ketersediaan PRS nya [3].

Pada penelitian ini telah dilakukan survey Heat Exchanger pada Pressure Reducing System (PRS) terpasang adalah dengan kapasitas $200 \mathrm{~m}^{3} / \mathrm{jam}$, sedangkan pemakaian CNG untuk proses produksi adalah $150 \mathrm{~m}^{3} / \mathrm{jam}$. Temperatur CNG setelah keluar dari PRS terbaca pada thermometer adalah sebesar $50^{\circ} \mathrm{C}$. Dari data-data tersebut dapat disimpulkan bahwa heat exchanger tersebut lebih besar dari kapasitas yang dibutuhkan. Agar didapatkan heat exchanger yang sesuai dengan kapasitasnya yaitu $150 \mathrm{~m}^{3} / \mathrm{jam}$ maka akan dilakukan rancang ulang sesuai dengan kapasitas tersebut. Menurut Sugiyanto, telah dilakukan penelitian untuk analisa alat penukar kalor tipe shell and tube yang disimulasikan dengan aplikasi perhitungan dengan microsoft visual basic 6.0 [4]. Hal-hal yang telah dilakukan perhitungan seperti beda suhu rata-rata, faktor pengotor, penurunan tekanan serta efisiensi efektif.

\section{MATERIAL DAN METODOLOGI}

\subsection{Konsep rancangan}

Pada dasarnya konsep perancangan merupakan suatu usaha untuk dapat memenuhi persyaratan-persyaratan yang diperlukan dalam pembuatan suatu alat sehingga memungkinkan untuk memperoleh hasil (produk) yang terbaik sesuai dengan keinginan. Dalam konsep perancangan ada beberapa metode yang dilakuakan salah satunya Varien Deutscher Ingenieure 2221 (VDI 2221).

Bagian yang paling penting dari metode perancangan adalah memecahkan masalah teknik dengan menggunakan tahap demi tahap secara analisis dan sintesis. Pada kenyataannya suatu tahap merupakan suatu proses yang kompleks, biasanya untuk memecahkan dibutuhkan suatu iterasi. Iterasi adalah suatu proses dimana suatu solusi dicapai secara tahap demi tahap. 
Metode VDI 2221 yang disusun oleh Gerhard Pahl dan Wolfgang Beitz [5] dalam buku Engineering Design ini dibagi beberapa tahapan yaitu:

a) Penjelasan tugas (clarifying the task)

b) Perancangan konsep (conceptual design)

c) Perancangan bentuk/wujud (embodiment design)

d) Perancangan detail/seutuhnya (detail design)

\subsection{Alat dan Bahan}

Persiapan alat dan bahan dalam penelitian ini meliputi :

1) Meteran

2) Thermometer

3) Pressure gauge

4) Kamera

\subsection{Penjelasan rancangan}

Dalam tahap ini dilakukan mengumpulkan informasi dan menguraikannya sejelas mungkin dalam bentuk daftar spesifikasi (requirement list), Serta mengidentifikasikan kendala-kendala yang dihadapi untuk mencapai solusi optimal. Yang harus diperhatikan dalam menyiapkan daftar spesifikasi membedakan sebuah persyaratan apakah sebagai keharusan (demand) atau keinginan (wishes). Daftar kebutuhan perancangan seperti pada Tabel 1.

Tabel 1. Daftar Kebutuhan Perancangan [5]

\begin{tabular}{|c|c|}
\hline & Daftar Spesifikasi \\
\hline Demand or Wishes & Persyaratan \\
\hline & Dimensi \\
\hline $\mathrm{D}$ & $\overline{\text { Ukuran tidak terlalu besar }}$ \\
\hline \multirow[t]{2}{*}{$\mathrm{D}$} & Mudah untuk dipindahkan \\
\hline & Material \\
\hline $\mathrm{D}$ & $\begin{array}{l}\text { Material yang digunakan untuk heat exchanger : kuat, mudah menghantarkan panas dan tahan } \\
\text { terhadap korosi }\end{array}$ \\
\hline $\mathrm{D}$ & Komponen tidak mudah karatan \\
\hline \multirow[t]{2}{*}{$\mathrm{W}$} & Umur penggunaan yang lama \\
\hline & Energi \\
\hline \multirow[t]{2}{*}{$\mathrm{D}$} & Menggunakan listrik \\
\hline & Ergonomis \\
\hline $\mathrm{D}$ & Pengoperasian mudah \\
\hline $\mathrm{D}$ & Ramah lingkungan \\
\hline \multirow[t]{2}{*}{ D } & Nyaman dalam pengoperasian \\
\hline & Keselamatan \\
\hline \multirow[t]{2}{*}{$\mathrm{D}$} & 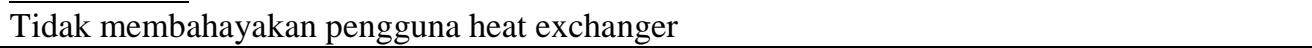 \\
\hline & Perawatan \\
\hline $\mathrm{D}$ & Tidak memerlukan perawatan khusus \\
\hline \multirow[t]{4}{*}{$\mathrm{D}$} & Pergantian atau pemasangan komponen yang rusak mudah dilakukan \\
\hline & Perakitan \\
\hline & 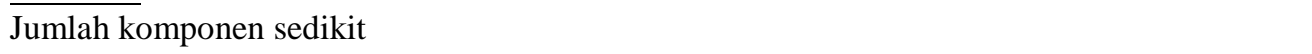 \\
\hline & Biaya \\
\hline $\mathrm{W}$ & Cukup murah \\
\hline
\end{tabular}

\subsection{Perancangan Konsep}

Adapun yang dibahas dalam perancangan konsep (Conceptual Design) heat exchanger ini meliputi abstraksi, pembuatan struktur fungsi, pencarian dan kombinasi prinsip solusi, pemilihan kombinasi yang sesuai, pembuatan varian konsep serta evaluasi.

1) Abstraksi

Abstraksi digunakan memecahkan masalah utama yang berdasarkan pada pendapat dan ide yang dituangkan dalam perancangan, artinya adalah mengesampingkan hal-hal yang bersifat khusus dan menekankan pada hal-hal bersifat umum.

2) Struktur fungsi

Setelah masalah utama diketahui, kemudian dibuat struktur fungsi secara keseluruhan. Struktur fungsi ini digambarkan dengan balok diagram yang menunjukan hubungan input dan output. Input dan output berupa aliran energi, material dan sinyal. Fungsi keseluruhan dibuat setelah kita menentukan tugas dari bagian yang dirancang 
secara keseluruhan yang menjalankan tugas secara terperinci. Tahap pertama yang dibuat adalah mekanisme heat exchanger untuk aliran gas.

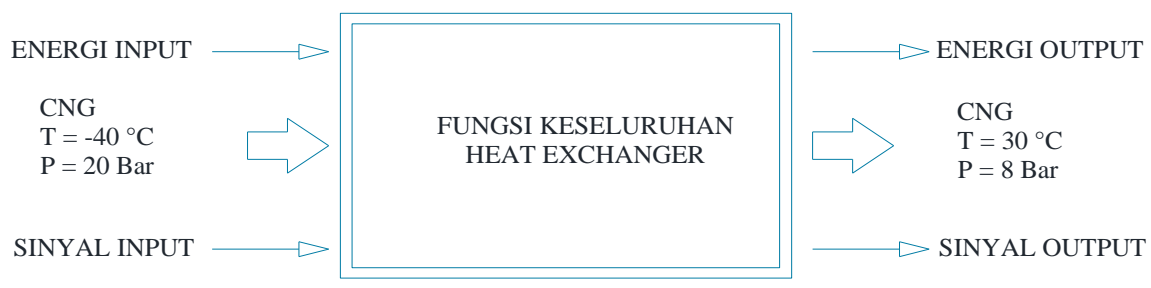

Gambar 1. Struktur Fungsi Keseluruhan

3) Pencarian prinsip

Dalam pencarian prinsip solusi dari masing-masing sub-fungsi ditekankan bahwa untuk mendapatan sebanyak mungkin variasi solusi. Menurut Pahl-Beitz, metode pencarian prinsip pemecah masalah dibagi menjadi empat kategori, yaitu:
a. Metode konvensional
b. Metode intuitif
c. Metode dikursif
d. Metode kombinasi

4) Pengkombinasian prinsip solusi

Dalam proses ini perancangan yang menggunakan metode kombinasi solusi masalah diperoleh dengan melakukan pemilihan terhadap minimal satu prinsip satu solusi untuk setiap sub fungsi.

5) Kombinasi dan pemilihan kombinasi prinsip solusi

Dalam perancangan dan pembuatan heat exchanger ini dipergunakan metode kombinasi. Untuk mendapatkan kombinasi terbaik harus dilakukan pengeleminasian dan pemilihan. Kriteria yang harus diperhatikan dalam memilih kombinasi adalah:

a. Sesuai dengan fungsi keseluruhan

b. Memenuhi demand dari daftar spesifikasi

c. Dapat diwujudkan

d. Sesuai dengan biaya yang diijinkan

6) Pembuatan konsep varian

Dalam pembuatan konsep varian kita harus memperhatikan segi teknik dan ekonominya. Konsep varian dapat di buat berdasarkan data-data di bawah ini:

a. Sketsa dan kemungkinan bentuk rancangan dan bentuk fisiknya

b. Perhitungan kasar yang didasarkan pada asumsi

c. Penelitian lebih lanjut untuk pengembangan teknologi

d. Riset lapangan untuk penganalisaan

e. Pengujian model untuk menentukan unjuk kerja secara kuantitatif

7) Evaluasi

Konsep varian yang telah dibuat harus dievaluasi satu persatu. Evaluasi berarti menentukan harga, keuntungan, kekuatan sebuah solusi apakah memenuhi tujuan. Evaluasi ini termasuk membandingkan sebuah solusi dengan solusi yang dianggap ideal. Dalam mengevaluasi konsep ini kita dapat menggunakan metode Guide Line VDI 2221 yang merupakan kombinasi evaluasi dari segi teknik dan ekonomi. Pada tabel 2 disajikan nilai dai Guide Line VDI 2221 beserta artinya.

Tabel 2. Guide Line VDI $2221^{[5]}$

\begin{tabular}{cc}
\hline Skala Nilai & Arti \\
\hline Point & Tidak memuaskan \\
\hline 0 & Dapat ditolerir \\
\hline 1 & Cukup/memadai \\
\hline 2 & Baik \\
\hline 3 & Sangat baik \\
\hline 4
\end{tabular}

\section{HASIL DAN PEMBAHASAN}

Pada Gambar 2 berikut merupakan skematik dari rangkaian pressure reducing system yang dimulai dari tabung gas yang berada di mobil pengangkut sampai ke meter gas. 


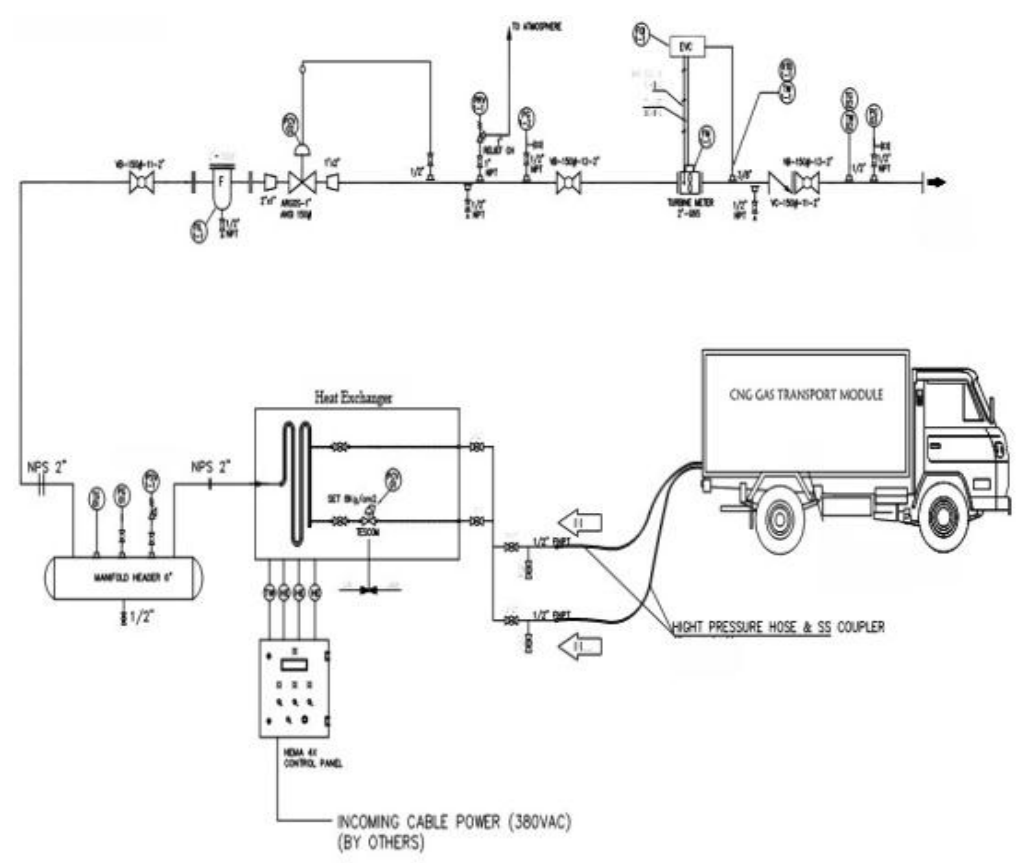

Gambar 2. Skematik Pressure Reducing System

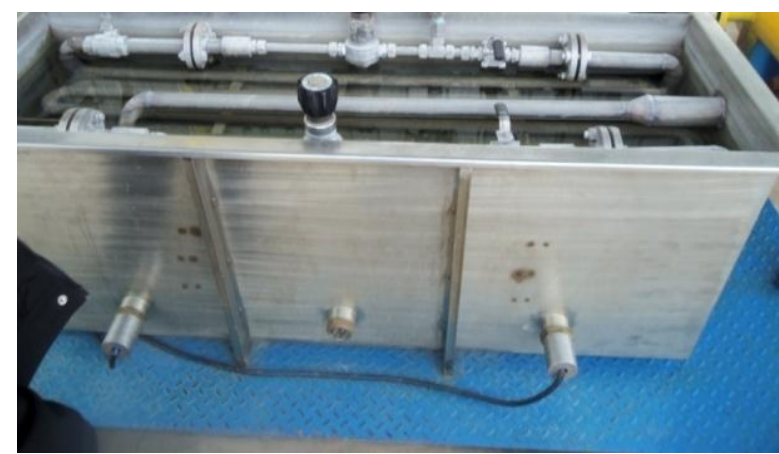

Gambar 3. Heat Exchanger yang terpasang

Langkah pertama sebagai acuan dasar perbandingan dengan heat exchanger rancang ulang, maka dilakukan terlebih dahulu perhitungan untuk heat exchanger yang telah dilakukan penelitian. Pada heat exchanger yang terpasang adalah memiliki kapasitas $200 \mathrm{~m} / \mathrm{jam}$, tetapi alat ini dipakai untuk konsumen dengan kapasitas $150 \mathrm{~m}^{3} / \mathrm{jam}$. Pada Tabel 3 merupakan data-data hasil survey untuk heat exchanger terpasang.

Tabel 3. Data PRS yang disurvey

\begin{tabular}{llll}
\hline No. & Parameter & Nilai & Satuan \\
\hline \hline 1 & Diameter luar Tube $\left(\mathrm{OD}_{\mathrm{t}}\right)$ & 0.0334 & $\mathrm{~m}$ \\
\hline 2 & Diameter Dalam Tube $\left(\mathrm{ID}_{\mathrm{t}}\right)$ & 0.0264 & $\mathrm{~m}$ \\
\hline 3 & Temperatur fluida masuk Tube $\left(\mathrm{T}_{\mathrm{c}, \mathrm{i}}\right)$ & -40 & $\mathrm{C}$ \\
\hline 4 & Temperatur fluida keluar Tube $(\mathrm{Tc}, \mathrm{o})$ & 50 & $\mathrm{C}$ \\
\hline 5 & Kapasitas & 0.042 & $\mathrm{~m}^{3} / \mathrm{s}$ \\
\hline 6 & Fluida yang dipanaskan & $\mathrm{CNG}($ Methane $)$ & \\
\hline 7 & Pressure Inlet $\left(\mathrm{P}_{\text {in }}\right)$ & $2 \times 10^{6}$ & $\mathrm{~Pa}$ \\
\hline 8 & Pressure Outlet $\left(\mathrm{P}_{\text {out }}\right)$ & $8 \times 10^{5}$ & $\mathrm{~Pa}$ \\
\hline 9 & Temperatur fluida air $\left(\mathrm{T}_{\mathrm{h}, \mathrm{i}}\right)$ & 60 & $\mathrm{C}$ \\
\hline 10 & Temperatur fluida air $\left(\mathrm{T}_{\mathrm{h}, \mathrm{o}}\right)$ & 40 & $\mathrm{C}$ \\
\hline 11 & Jumlah Tube & 27 & $\mathrm{Buah}$ \\
\hline 12 & Jarak Pitch & 0.05 & $\mathrm{~m}$ \\
\hline 13 & Panjang Tube & 1.3 & $\mathrm{~m}$ \\
\hline 14 & Panjang Total Tube $(\mathrm{L})$ & 35.1 & $\mathrm{~m}$ \\
\hline 15 & Pass tube & 1 & $\mathrm{Pass}$ \\
\hline 16 & Ukuran bak (shell $)$ & $1.5 \times 0.5 \times 1$ & $\mathrm{~m}$ \\
\hline
\end{tabular}


Ramadhan dkk., Rancang Ulang Heat Exchanger Shell And Tube Pada Pressure Reducing System Untuk Compressed Natural Gas Kapasitas 150 $\mathrm{m}^{3} / \mathrm{Jam}$

Efektivitas alat penukar kalor diperoleh dari persamaan [6] berikut:

$$
\varepsilon=\frac{Q}{Q_{\max }}
$$

Perpindahan kalor maksimum:

$$
\mathrm{Q}_{\max }=\mathrm{C}_{\min } \mathrm{x}\left(\mathrm{T}_{\mathrm{h}, \mathrm{i}}-\mathrm{T}_{\mathrm{c}, \mathrm{i}}\right)
$$

Kapasitas kalor yang minimum dipilih dari:

$$
\begin{aligned}
& \mathrm{C}_{\mathrm{c}}=\mathrm{m}_{\mathrm{c}} \times \mathrm{Cp}_{\mathrm{c}}=2.94 \times 2087=6135,78 \mathrm{~W} / \mathrm{K} \\
& \mathrm{C}_{\mathrm{h}}=\mathrm{m}_{\mathrm{h}} \times \mathrm{Cp}_{\mathrm{h}}=6,61 \times 4178=27616,58 \mathrm{~W} / \mathrm{K}
\end{aligned}
$$

Diperoleh:

$$
\mathrm{Q}_{\max }=6135,78 \times(60-(-40))=613578 \mathrm{~W}
$$

Diperoleh efektivitas alat penukar kalor adalah :

$$
\varepsilon=\frac{552220,2}{613578} \times 100 \%=90 \%
$$

Selanjutnya hasil perhitungan untuk perancangan ulang heat exchanger dengan kapasitas CNG $150 \mathrm{~m}^{3} / \mathrm{jam}$. Data-data hasil perancangan seperti tercantum pada Tabel 4 berikut.

Tabel 4. Data heat exchanger rancang ulang

\begin{tabular}{llll}
\hline No. & Parameter & Nilai & Satuan \\
\hline \hline 1 & Diameter luar Tube $\left(\mathrm{OD}_{\mathrm{t}}\right)$ & 0.0334 & $\mathrm{~m}$ \\
\hline 2 & Diameter Dalam Tube $\left(\mathrm{ID}_{\mathrm{t}}\right)$ & 0.0264 & $\mathrm{~m}$ \\
\hline 3 & Temperatur fluida masuk Tube $\left(\mathrm{T}_{\mathrm{c}, \mathrm{i}}\right)$ & -40 & $\mathrm{C}$ \\
\hline 4 & Temperatur fluida keluar Tube $(\mathrm{Tc}, \mathrm{o})$ & 30 & $\mathrm{C}$ \\
\hline 5 & Kapasitas & 0.042 & $\mathrm{~m}^{3} / \mathrm{s}$ \\
\hline 6 & Fluida yang dipanaskan & $\mathrm{CNG}($ Methane $)$ & \\
\hline 7 & Pressure Inlet $\left(\mathrm{P}_{\text {in }}\right)$ & $2 \times 10^{6}$ & $\mathrm{~Pa}$ \\
\hline 8 & Pressure Outlet $\left(\mathrm{P}_{\text {out }}\right)$ & $8 \times 10^{5}$ & $\mathrm{~Pa}$ \\
\hline 9 & Temperatur fluida air $\left(\mathrm{T}_{\mathrm{h}, \mathrm{i}}\right)$ & 60 & $\mathrm{C}$ \\
\hline 10 & Temperatur fluida air $\left(\mathrm{T}_{\mathrm{h}, \mathrm{o}}\right)$ & $\mathrm{C}$ \\
\hline 11 & Jumlah Tube & 40 & $\mathrm{Buah}$ \\
\hline 12 & Jarak Pitch & 26 & $\mathrm{~m}$ \\
\hline 13 & Panjang Tube & 0.05 & $\mathrm{~m}$ \\
\hline 14 & Panjang Total Tube & 0.85 & $\mathrm{~m}$ \\
\hline 15 & Pass tube & 22 & $\mathrm{Pass}$ \\
\hline 16 & Ukuran bak $($ shell $)$ & 1 & $\mathrm{~m}$ \\
\hline
\end{tabular}

Efektivitas alat penukar kalor diperoleh dari persamaan :

$$
\varepsilon=\frac{Q}{Q_{\max }}
$$

Perpindahan kalor maksimum

$$
\mathrm{Q}_{\max }=\mathrm{C}_{\min } \mathrm{X}\left(\mathrm{T}_{\mathrm{h}, \mathrm{i}}-\mathrm{T}_{\mathrm{c}, \mathrm{i}}\right)
$$

Kapasitas kalor yang minimum dipilih dari

$$
\begin{aligned}
& \mathrm{C}_{\mathrm{c}}=\mathrm{m}_{\mathrm{c}} \times \mathrm{Cp}_{\mathrm{c}}=2,94 \times 2087=6135,78 \mathrm{~W} / \mathrm{K} \\
& \mathrm{C}_{\mathrm{h}}=\mathrm{m}_{\mathrm{h}} \times \mathrm{Cp}_{\mathrm{h}}=5,15 \times 4178=21516,7 \mathrm{~W} / \mathrm{K}
\end{aligned}
$$


Diperoleh:

$$
\mathrm{Q}_{\max }=6135,78 \times(60-(-40))=613578 \mathrm{~W}
$$

Diperoleh efektivitas alat penukar kalor sebesar:

$$
\varepsilon_{\mathrm{b}}=\frac{429504,6}{613578} \times 100 \%=70 \%
$$

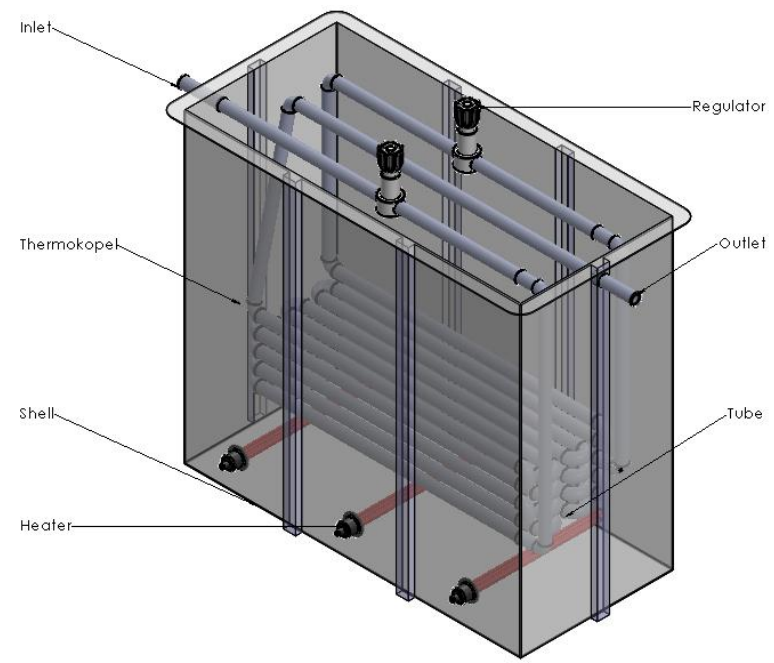

Gambar 4. Heat exchanger hasil rancang ulang

Dari data-data tersebut diatas bahwa dapat disimpulkan bahwa dengan kapasitas pressure reducing system yang lebih besar untuk pemakaian kapasitas kecil akan didapatkan efektivitas yang lebih tinggi. Sedangkan untuk pemakaian yang sesuai kebutuhan hanya diperoleh efektivitas $70 \%$. Keuntungan yang dapat diambil adalah dari segi konstruksi yaitu efisiensi material dan ruang yang lebih kecil dibandingkan dengan PRS yang ada.

\section{KESIMPULAN}

Dari penelitian yang dilakukan terhadap PRS yang terpasang ataupun perhitung PRS rancang ulang sesuai kapasitas yang dibutuhkan dapat diambil beberapa kesimpulan sebagai berikut :

1) Dengan PRS kapasitas $200 \mathrm{~m}^{3} / \mathrm{jam}$ digunakan untuk kapasitas $150 \mathrm{~m}^{3} / \mathrm{jam}$ maka didapatkan efektivitas sebesar $90 \%$ dengan temperatur output lebih tinggi yaitu $50^{\circ} \mathrm{C}$, lebih besar dari yang dibutuhkan.

2) Dengan PRS kapasitas $150 \mathrm{~m}^{3} / \mathrm{jam}$ digunakan untuk kapasitas $150 \mathrm{~m}^{3} / \mathrm{jam}$ maka didapatkan efektivitas sebesar $70 \%$ dengan temperatur output $30^{\circ} \mathrm{C}$, sesuai yang dibutuhkan.

3) Semakin tinggi temperatur yang diberikan oleh fluida panas (air) maka efisiensi yang didapat semakin tinggi. Tetapi temperatur fluida panas tetap dijaga agar memudahkan operator untuk pengaturan regulator (penurun tekanan).

4) Dengan pemakaian PRS yang sesuai kapasitas, maka akan didapatkan efisiensi biaya pembuatan PRS dan pemakaian ruang yang lebih kecil, sehingga bisa membuat harga lebih bersaing.

\section{REFERENSI}

[1] Handoyo, Y dan Ahsan, 2012, Analisa Kinerja Penukar Kalor Jenis Shell dan Tube pada Pendingin Aliran Air pada PLTA Jatiluhur, Jurnal Energi dan Manufaktur, Vol. 5, No. 1, pp. 42-50.

[2] Setyoko, B, 2008, Evaluasi Kenerja Heat Exchanger Dengan Metode Fouling Factor, Jurnal Teknik, Vol.29 N0.2, ISSN 0852-1697, pp. 148-153.

[3] Zacharias, P dan Pancoko, M, 2011, Rekayasa Heat Exchanger Sebagai Pemanas Umpan UF6 Ke Reaktor Rotary Kiln, Prosiding Pertemuan Ilmiah Rekayasa Perangkat Nuklir, PRPN-BATAN, 175-186.

[4] Sugiyanto, Analisa Alat Penukar Kalor Tipe Shell and Tube yang Disimulasikan dengan Aplikasi Perhitungan dengan Microsoft Visual Basic 6.0, Universitas Gunadarma

[5] Pahl, G dan Beitz, W, 1984, Engineering Design, The Design Council, London

[6] Cengel, Y.A., 2008, Introduction to Thermodynamics and Heat Transfer, McGraw-Hill Higher Education, Nevada 